\title{
Endoscopic mucosal resection of esophageal squamous papillomatosis
}

\author{
Edward Kim MD CCFP FRCPC ${ }^{1}$, Michael F Byrne MD FRCPC ${ }^{2}$, Fergal Donnellan MD FRCPC ${ }^{2}$
}

\begin{abstract}
A 62-year-old woman was referred for investigation of heartburn. She did not have any other significant medical history and denied any other symptoms including weight loss, dysphagia, odynophagia, regurgitation and hematemesis. Her only medication was pantoprazole $40 \mathrm{mg}$ daily for her gastroesophageal reflux disease. Endoscopy was performed with a GIF-Q180 gastroscope (Olympus Optical, Japan), which demonstrated multiple flesh-coloured pedunculated papules at the gastroesophageal junction (Figure 1). Biopsies demonstrating atypical epithelial proliferation confirmed the diagnosis of esophageal squamous papillomatosis, without the presence of dysplasia or carcinoma. A polymerase chain reaction study was negative for herpes simplex virus. Following discussion with the patient, an extensive endoscopic mucosal resection (EMR) incorporating all of the lesions was performed using a band mucosectomy device (Duette, Cook Medical, Ireland) (Figures 2 and 3). Histology from the EMR specimens was similar to the original mucosal biopsy results. No immediate or delayed complications occurred.
\end{abstract}

\section{DISCUSSION}

Although first described in 1959 (1), squamous papilloma of the esophagus is a rare endoscopic finding, occurring in $0.01 \%$ of individuals at autopsy and $0.07 \%$ of patients during routine endoscopy (2). There is a reported variability in the geographical distribution of this lesion, with a high prevalence in Europe, accounting for approximately $75 \%$ of the reported cases. This lesion is usually an incidental finding as a small $(<0.5 \mathrm{~cm})$ single lesion, most commonly located in the distal esophagus (3).

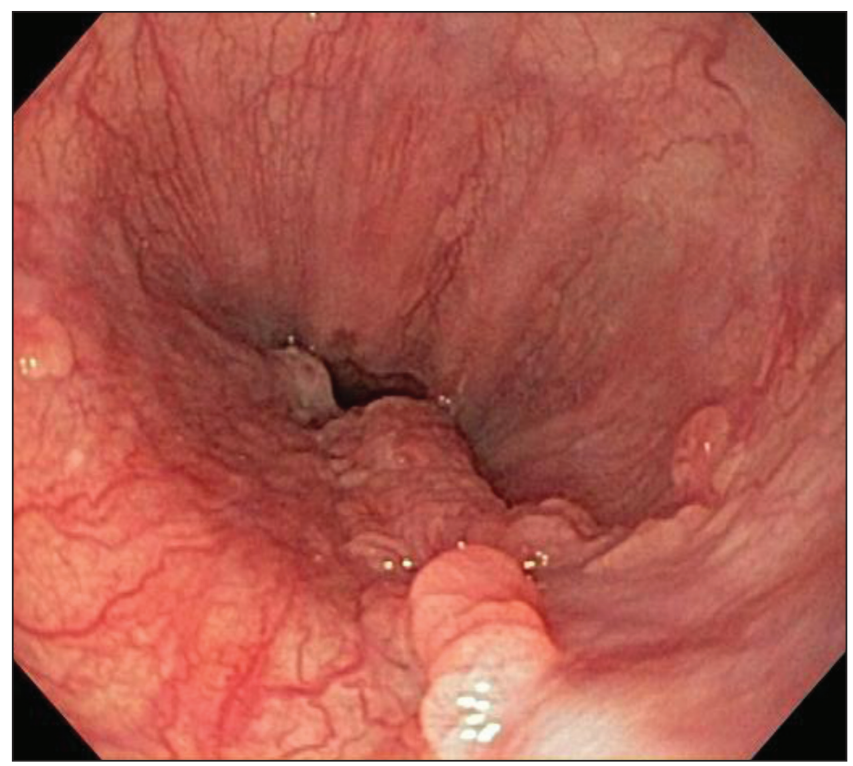

Figure 1) Squamous papillomatosis
Squamous papillomas are typically reported as fleshy-pink in colour, with a soft to warty texture and exist in either sessile or pedunculated form. While the typical endoscopic appearance is a single, round sessile lesion, they can present with multiple esophageal lesions, with rare reports of papillomas exceeding $1 \mathrm{~cm}$ in diameter (4). Histologically, they are characterized by vascular connective tissue stalks branching out from the lamina propria with an overlying hyperplastic squamous epithelium. Normal cellular orientation and differentiation are preserved and, unlike squamous cell carcinoma, atypical mitoses or dysplastic cellular invasion into the submucosa are absent. Squamous papillomas of the esophagus are typically asymptomatic, but can be associated with dysphagia, with clinical improvement after removal (5). The predilection of squamous papillomas for the distal esophagus, in addition to its common association with surrounding changes of histological changes of reflux esophagitis, has supported the theory that chemical irritation from reflux of acidic gastric contents has a role in their development. Chemical induction of esophageal papillomas has been demonstrated in experimental animal models. Chemical agents produce leukoplakia, resulting in verrucous hyperplasia of the epithelium that can lead to papilloma formation (6). Our patient had multiple distal esophageal squamous papillomas, otherwise known as squamous papillomatosis, which is even less common than single papillomas. A literature review identified only nine such cases of squamous papillomatosis, some which were positive for human papillomavirus (HPV). Syrjanen et al (7) demonstrated an association with HPV. However, squamous papillomatosis can be found in the absence of HPV.

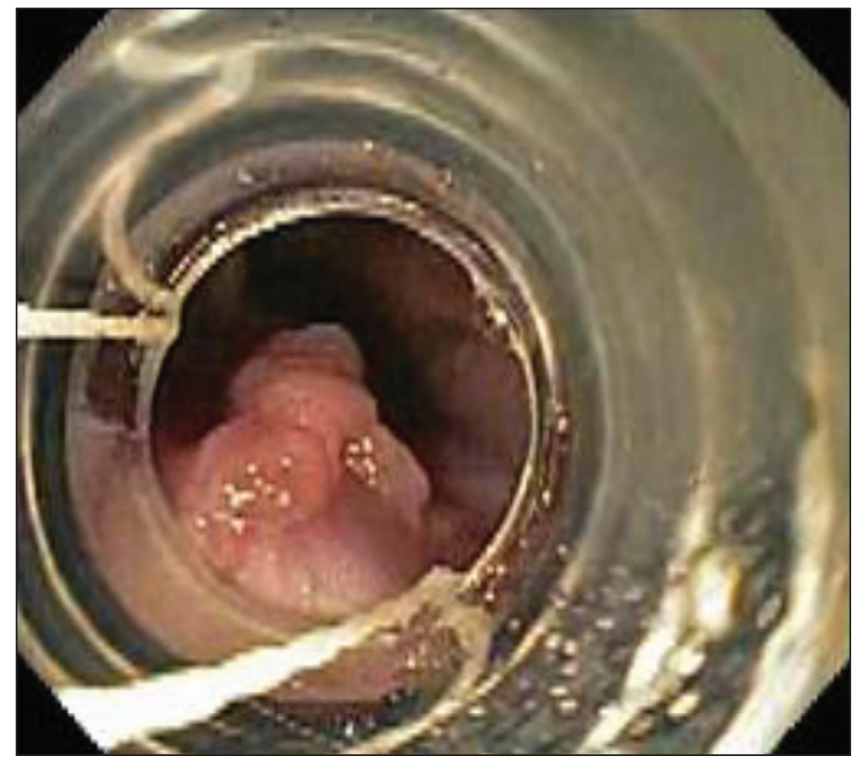

Figure 2) Endoscopic mucosal resection

${ }^{1}$ Department of Medicine; ${ }^{2}$ Division of Gastroenterology, Vancouver General Hospital, University of British Columbia, Vancouver, British Columbia Correspondence: Dr Edward Kim, Gastroenterology Fellowship, University of British Columbia, 5th Floor, Leslie and Diamond Centre, 2775 Laurel

Street, Vancouver, British Columbia V5Z 1M9. Telephone 604-875-5244, fax 604-875-5447, e-mail edkim111@gmail.com

Received for publication June 25, 2012. Accepted July 12, 2012 
The natural history of papillomatosis is controversial, with early reports suggesting that it was a benign condition and that endoscopic surveillance was unnecessary (2). More recently, there have been multiple reports of malignancy found within squamous papillomas. This has led some authors to recommend that esophageal papillomatosis be considered a premalignant condition with the potential for the development of squamous cell carcinoma (8). Interestingly, the reported cases of carcinoma involved extensive papillomatosis rather than isolated lesions.

The management of esophageal papillomatosis has not been clearly defined in the literature. Small isolated lesions have been successfully treated with endoscopic resection using biopsy forceps, snare polypectomy and cautery (4). The management of multiple esophageal lesions can be more challenging and, due to the paucity of reported cases, the optimal clinical management of extensive papillomatosis remains unclear. Photodynamic therapy and radiofrequency ablation may also be useful treatment options (9). Surgical resection has even been advocated when malignancy is suspected but not demonstrated in biopsies (10). If no specific treatment is undertaken, surveillance endoscopy should be considered given the potential for development of malignancy. However, the specific surveillance strategy has not yet been characterized. To our knowledge, the present report describes the first successful removal of multiple esophageal squamous papillomas using EMR (Duette band mucosectomy device).

Squamous papillomas of the esophagus are a rare finding during endoscopy, but have the potential for malignant transformation in some cases. Optimal management of these lesions has not been established; however, removal of these lesions during endoscopy using EMR is a reasonable option.

\section{REFERENCES}

1. Adler RH, Carberry DM, Ross CA. Papilloma of the esophagus:

Association with hiatal hernia. J Thorac Surg 1959;37:625-35.

2. Mosca S, Manes G, Monaco R, Bellomo PF, Bottino V, Balzano A.

Squamous papilloma of the esophagus: Long-term follow up.

J Gastroenterol Hepatol 2001;16:857-61.

3. Politoske EJ. Squamous papilloma of the esophagus associated with the human papillomavirus. Gastroenterology 1992;102:668-73.

4. Tabatabaei SA, Moghadam NA, Ahmadinejad M,

Mirmohammadsadeghi A, Masoudpour H, Adibi P.

Giant esophageal squamous papilloma: A case report.

J Dig Dis 2009;10:228-30.

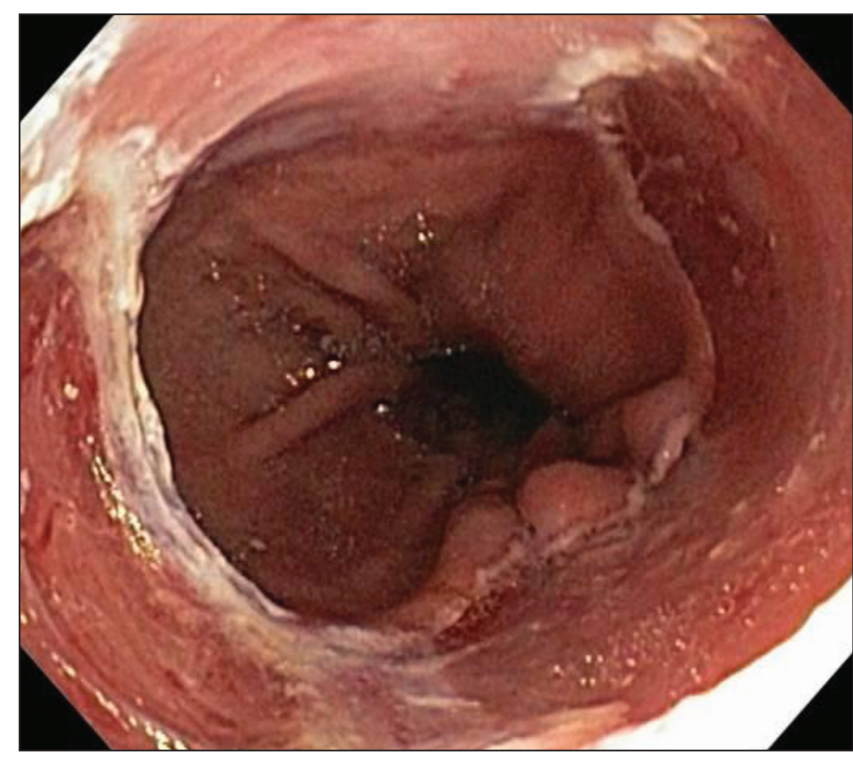

Figure 3) Post-resection

5. Benisch BM, Mantell C. Multiple squamous papillomas of the esophagus. Arch Otolaryngol 1974;100:379.

6. Napalkov NP, Pozharisski KM. Morphogenesis of experimental tumors of the esophagus. J Natl Cancer Inst 1969;42:927-40.

7. Syrjanen K, Pyrhonen S, Aukee S, Koskela E. Squamous cell papilloma of the esophagus: A tumour probably caused by human papilloma virus (HPV). Diagn Histopathol 1982;5:291-6.

8. Attila T, Fu A, Gopinath N, Streutker CJ, Marcon NE. Esophageal papillomatosis complicated by squamous cell carcinoma. Can J Gastroenterol 2009;23:415-9.

9. Kibria R, Akram S, Moezzi J, Ali S. Esophageal squamous papillomatosis with dysplasia. Is there a role of balloon-based radiofrequency ablation therapy? Acta Gastroenterol Belg 2009;72:373-6.

10. Tonna J, Palefsky JM, Rabban J, Campos GM, Theodore P, Ladabaum U. Esophageal verrucous carcinoma arising from hyperkeratotic plaques associated with human papilloma virus type 51. Dis Esophagus 2010;23:E17-20.

The Canadian Journal of Gastroenterology is now considering a limited number of submissions for IMAGE OF THE MONTH. These are based on endoscopic, histological, radiological and/or patient images, which must be anonymous with no identifying features visible. The patient must consent to publication and the consent must be submitted with the manuscript. All manuscripts should be practical and relevant to clinical practice, and not simply a case report of an esoteric condition. The text should be brief, structured as CASE PRESENTATION and DISCUSSION, and not more than 700 words in length. A maximum of three images can be submitted and the number of references should not exceed five. The submission may be edited by our editorial team.

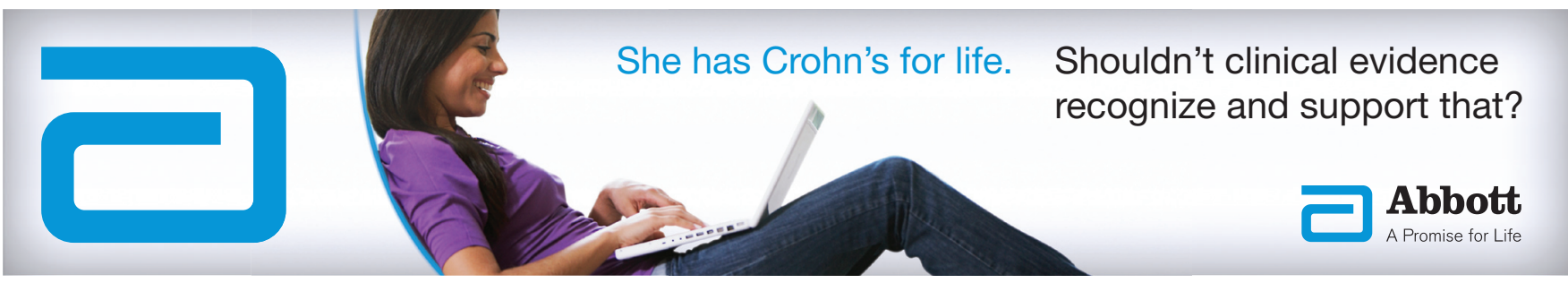




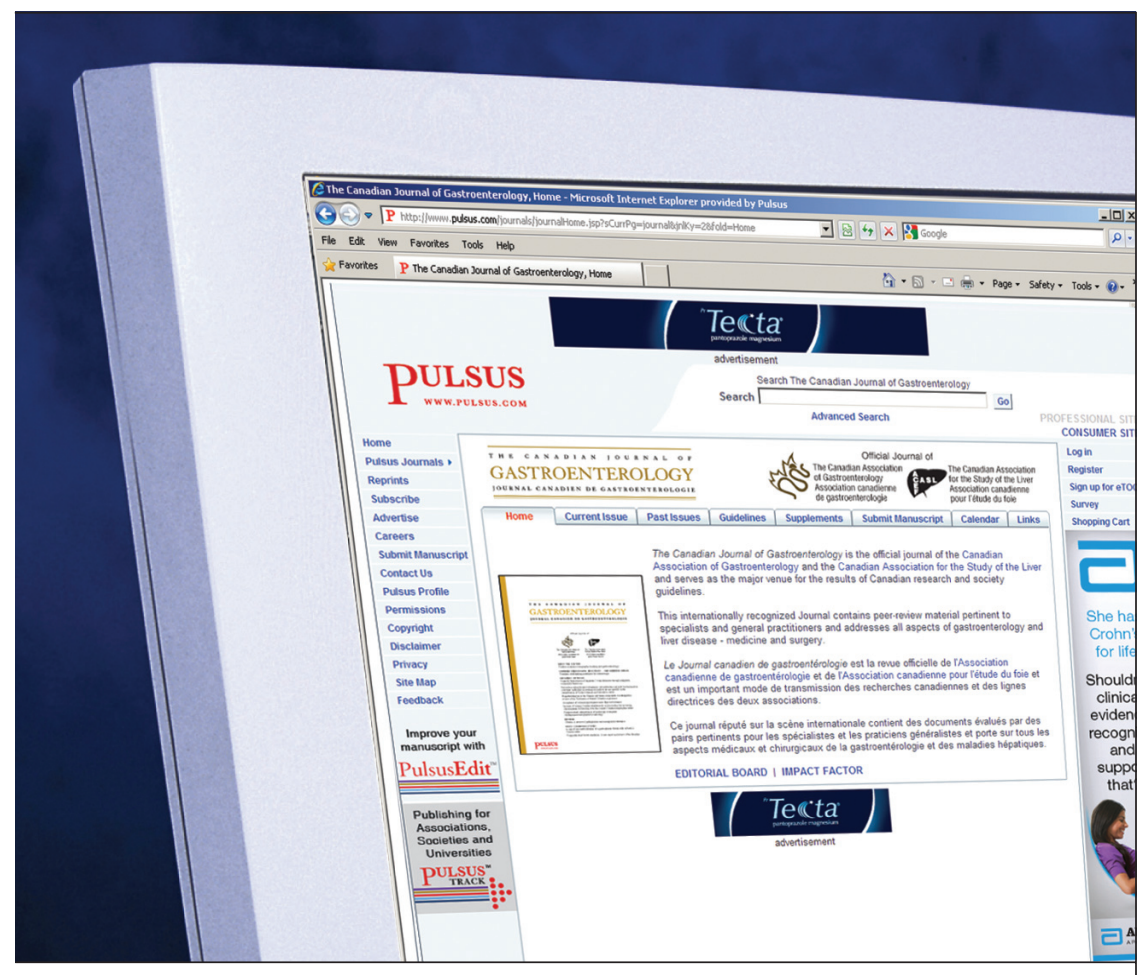

A SINCERE

THANK YOU TO

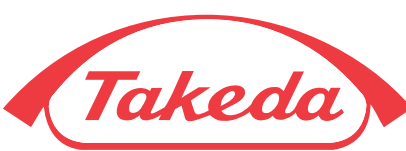

Takeda Canada Inc GOLD SPONSOR

GENEROUS SUPPORTERS OF THE

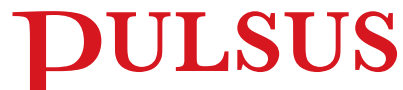

Canadian Journal of

Gastroenterology

WEBSITE

\section{Abbott Laboratories Ltd}

SILVER AND BRONZE SPONSOR

\section{AUTHORS:}

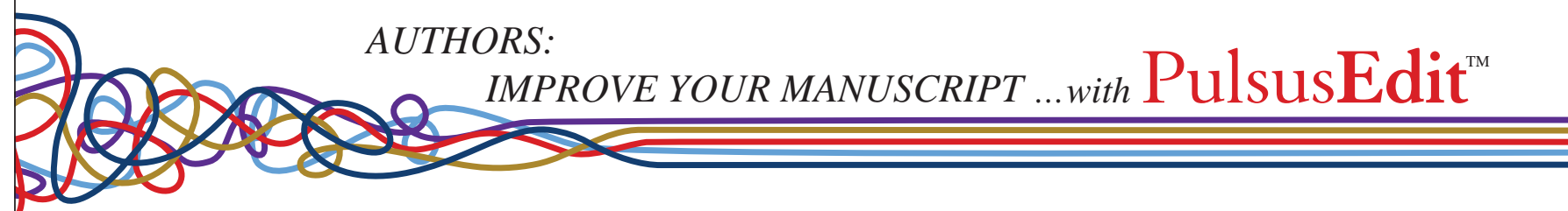

\section{PulsusEdit.com - Manuscript Editing Service}

PulsusEdit ${ }^{T m}$ (a division of Pulsus Group Inc.) is a service that provides scientific editorial assistance to authors of manuscripts in all medical/scientific disciplines, affording authors a greater likelihood of being accepted for publication in high impact factor journals.

\section{Experience \& Knowledge}

The PulsusEdit ${ }^{\mathrm{TM}}$ team has a strong background in scientific editing perfected by editing world-renown journals published by Pulsus Group Inc. Every member is a skilled and experienced professional that will ensure your manuscript is grammatically sound, readable and understandable, and delivers your message concisely. The same attention to detail that is used in editing articles featured in Pulsus Group Inc journals will be applied to your manuscript. It will be improved in every way, substantially increasing your opportunity for success.

\section{PulsusEdit ${ }^{\mathrm{Tm}}$ Services}

Two levels of service are available to authors.

- PulsusEdit ${ }^{\mathrm{TM}}$ Comprehensive Scientific Editing

This is has been established as an excellent level of editing. Your manuscript will be taken to the high standard exhibited in the Pulsus Group, peer-reviewed and indexed publications. It will be edited for grammar and sentence structure, all ambiguities are corrected, logic and flow is adjusted, facts are checked and we communicate with the author when major substantive changes are required.

- PulsusEdit ${ }^{\mathrm{TM}}$ Elite Scientific Editing

This superb level of editing includes all aspects of the Pulsus Comprehensive Scientific Editing package, but also includes an additional round of proofreading, editing and reviewing by a second Pulsus editor.

- Additional editorial services, including modification according to particular Instructions to Authors, are available upon request.

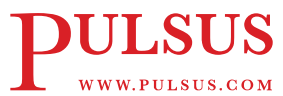

Go to PulsusE dit.com and submit your manuscript online for a no-obligation quote today, as a first step towards having your paper accepted by a high-impact journal. 


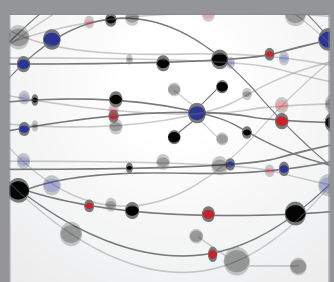

The Scientific World Journal
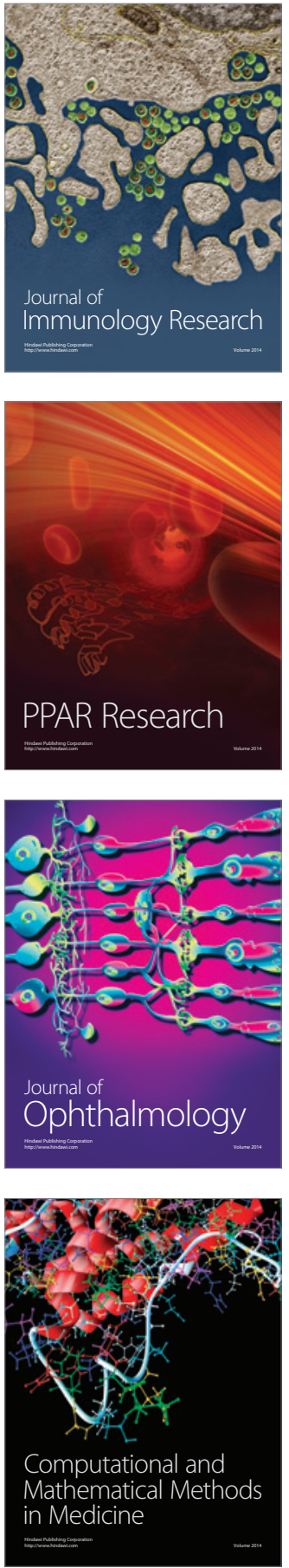

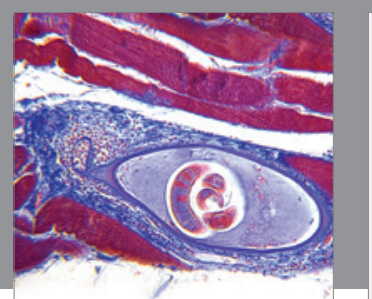

Gastroenterology Research and Practice

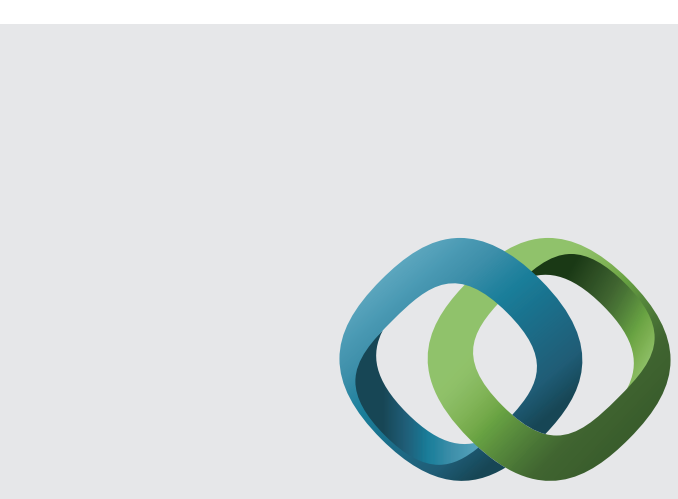

\section{Hindawi}

Submit your manuscripts at

http://www.hindawi.com
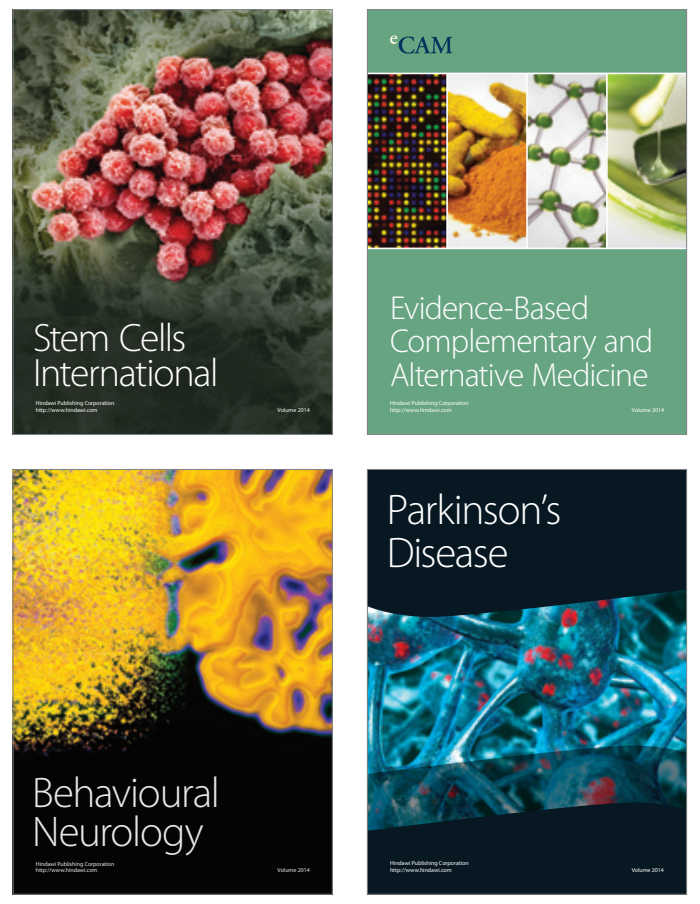
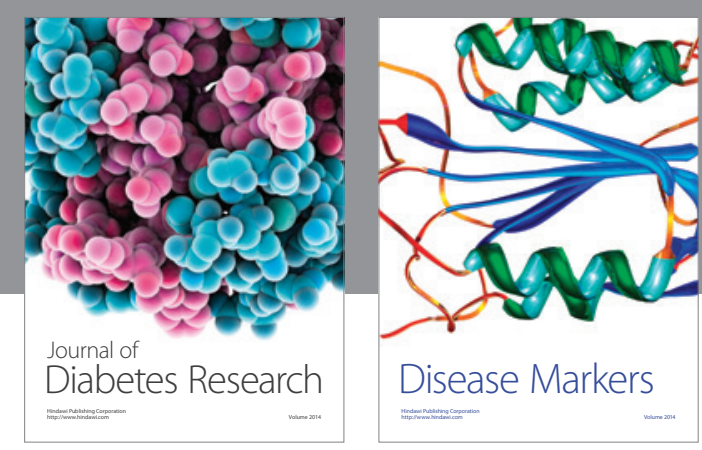

Disease Markers
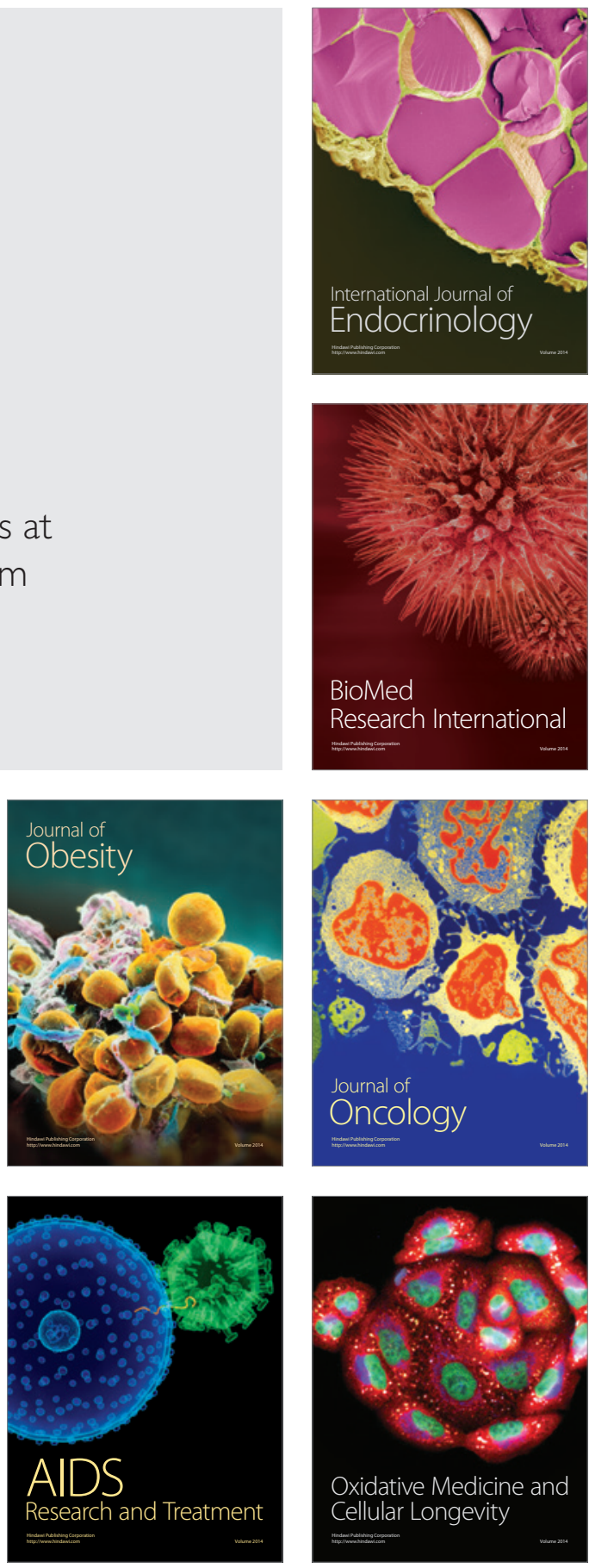